\title{
Certified Electronic Health Records and Quality of Health Care in Type II Diabetes Mellitus Patients
}

\author{
Tracey A Hines and Sajeesh Kumar* \\ Department of Health Informatics \& Information Management, University of Tennessee Health Science Center, Memphis, TN, USA
}

\begin{abstract}
Great strides have been made in health care over the past six years after the implementation of the policy known as meaningful use by the Center of Medicare and Medicaid Services in USA. Health care subsidies and monetary incentive programs were created for eligible professionals and critical area hospitals to encourage the use of certified electronic health records in an effort to improve quality care of all acute and chronically ill patients, as well as provide routine examinations for healthy individuals. Patients diagnosed with type II diabetes mellitus were studied using a certified electronic health record system for compliance in physician ordered lab testing and follow-up visits with their primary care physician so as to confirm a positive effect on in the quality of patient health care. Diabetes mellitus is a disease which requires constant monitoring, thus creating an ideal patient study group. Research has confirmed that patient compliance significantly improves quality of health care outcomes; now it is time to determine that if the implementation of a certified electronic health record in the family practice setting improves patient compliance, thus improving quality of health care.
\end{abstract}

Keywords: Clinical decision support; Type II diabetes mellitus; Electronic health record; Electronic medical services; Quality of health care; Evaluation of technology

\section{Introduction}

The Centers of Medicare and Medicaid Services (CMS) implemented the meaningful use (MU) incentive policy in 2009 to mandate how health care providers submit statistical reports on their patients [1]. Until then, there was no consistent method to evaluate follow-through visits and compliance with physician orders, lab work and prescription medication therapy. By 2009, the Health Information Technology for Economic Act addressed the adoption of meaningful use (MU) in electronic health records (EHRs) so that eligible professionals (EPs) such as health care providers, professionals and critical area hospitals had a means of meeting the criteria to receive incentives by way of reimbursements from the CMS [2,3]. One of the goals of $\mathrm{MU}$ is to improve patient quality of care by promoting patient compliance with orders initiated by their health care provider $[4,5]$. There are three stages of MU and the first deadline has already come to pass in 2014 [6,7]. The requirements to meet MU in health care organizations require that these facilities utilize and report statistics using certified EHR's.

Eligible professionals (EP) are comprised of individuals or groups meeting the eligibility requirements to utilize benefits from meaningful use initiatives. Other federal programs such as the Physician Quality Reporting Systems (PQRS) were established to regulate how quality reporting is performed by all EPs and are evaluated by the CMS (American Medical Association [8].

\section{Certified electronic health records}

It is believed by various health care organizations that current strategies for the certified EHR improve the way healthcare is received and delivered today [6]. EPs utilizing a certified EHR should be capable of capturing and sharing patient data accurately and efficiently [6]. A certified EHR facilitates the communication between two collaborating health care systems while sharing the same vocabulary. There are specific reviews of quality measures involved with each patient encounter which is tailored around the patient's specific health care needs; these measures act as reminders to establish the continuity of quality health care for the patient diagnosed with a chronic disease. For instance, the EHR used by a provider for patients being evaluated for type II diabetes mellitus (DM), will present the health care professional with a reminder to either check the patient's feet for ulcers or sores, or address that it is time to recheck essential lab work. DM patients have the potential to benefit from a certified EHR as it is capable of providing automatic reminder phone calls or texts about upcoming follow-up appointments, lab orders, current medication lists, as well as providing patient a summary for every visit, either in print or in a cloud-based, patient portal service. Patient portals are essentially a secure website where patients review their personal health information (PHI), literature about the patient's diagnoses, medications, and even bills. One quality of care measure reinforced by MU calculates the percentage of patients who were offered their summary of care after their visit. EPs utilizing certified EHRs are capable of creating this summary (customarily while in the exam room with the patient), based on the patient's individual diagnoses and problems. This is just one example of how MU and the certified EHR collaborate to keep the patient informed of their condition, appointments and the purpose of the medications and lab work the provider orders.

Certified EHR vendors have introduced technology allowing health care providers to perform their own statistical analysis of certain aspects of their practice; coincidentally most of them are capable of reporting MU data to CMS on a quarterly basis. Currently, MU involves implementing five clinical decision support rules including diagnostic test ordering as well as having the capability to track patient compliance [6]. Where it is not necessary for EP's to utilize an EHR which is certified to meet MU initiatives, the certification provides

*Corresponding author: Sajeesh Kumar, Associate Professor, Department of Health Informatics \& Information Management, University of Tennessee Health Science Center, 920 Madison Avenue Suite 518, Memphis, Tennessee 38163, USA, E-mail: skumar10@uthsc.edu

Received May 11, 2016; Accepted May 18, 2016; Published May 25, 2016

Citation: Hines TA, Kumar S (2016) Certified Electronic Health Records and Quality of Health Care in Type II Diabetes Mellitus Patients. J Health Med Informat 7: 231. doi:10.4172/2157-7420.1000231

Copyright: $\odot 2016$ Hines TA, et al. This is an open-access article distributed under the terms of the Creative Commons Attribution License, which permits unrestricted use, distribution, and reproduction in any medium, provided the original author and source are credited. 
an assurance to the health care professional that their efforts will be rewarded with both monetary incentives as well as patients offered the highest quality health care the provider an offer.

\section{Background}

DM is rapidly becoming a major epidemic in the United States. Health care professionals with a certified EHR have the opportunity to examine factors that can improve the quality of health in these patients. There is a limited amount of literature available, discussing the comparison between certified EHR use and patients with diabetes. Healthcare providers managing patients with chronic conditions such as DM should consider using a certified EHR system capable of meeting quality measures such as MU and PQRS. These measures are routinely evaluated and updated to incorporate the specific needs of the DM patient [9-18]. Both patients and health care providers would benefit from a study using a certified EHR to compile patient data and study the trends of patient follow-up visits, lab work values, and medication compliance.

\section{Purpose of Study}

The purpose of this study is to define patient quality of care and determine whether the MU is a positive influence on patients with type II diabetes mellitus. This study is intended to discover a correlation between the benefits of using a certified EHR for the patient reminders, data collected and compliance during the treatment for DM.

\section{Methodology}

An observational research method was used to perform a case study of a group of individuals with a common diagnosis of type II diabetes mellitus. The data was compiled in order to draw conclusions about patient compliance with follow up-appointments, physicianordered blood work and medication treatment compliance. This study will also evaluate changes in patients with type II diabetes mellitus and their $\mathrm{HbAlc}$ lab results and changes in BMI as a measure of changes in overall patient health over a given period of time.

There are five questions this study seeks to answer to determine whether a patient is experiencing an improvement in the quality health care, given the requirements of MU in implementing certified EHR systems in health care provider offices.

- Is there a direct correlation between the benefits of a certified EHR and patient compliancy in following up for their appointments as scheduled? The certified EHR of a family medical practice will be used to isolate all patients diagnosed with type II diabetes mellitus (ICD-9 250.00) and deliver data obtained from those patients. Patients will be subject to informed consent before this report is created and only those consenting patients will be evaluated for this question and those following.

- Is there a correlation between the benefits of a certified EHR and patient compliance with physician ordered lab work?

- Is there a correlation between the benefits of a certified EHR and changes in Low Density Lipoprotein Levels (LDL mg/dL)?

- Is there a correlation between the benefits of a certified EHR and changes in patient Body Mass Index $\left(\mathrm{BMI} \mathrm{kg} / \mathrm{m}^{2}\right)$ values?

- Is there a correlation between the benefits of a certified EHR and changes in patient Glycosylated Hemoglobin (HbA1c \%) values?

- Is there a correlation between the benefits of a certified EHR and patient compliance with purchasing and taking medication refills as prescribed?
Patients were selected from a single provider in Lawrenceburg, Tennessee. Patients were selected using the following criteria:

- Diagnosed with type II diabetes mellitus (ICD-9 code 250.00) previous to $9 / 15 / 2013$.

- Ongoing therapy for type II diabetes mellitus (ICD-9 code 250.00) with Dr. Gregory Hines at Family Medical Center, PLC from 9/15/2013 through 9/15/2015.

- Patients selected were between the ages of 25 through 80 at the time of the study.

- Patients must have been able to make their own decisions about complying with doctor's appointments, medications and therapy; patients in nursing homes, home health situations, or jail were omitted as to not give an advantage or disadvantage to the study.

\section{Selection results}

- Ninety-five (95) patients were initially pulled from the report generator of the certified electronic health record for Family Medical Center, PLC.

- Eleven patients (11) were automatically omitted from the study, as they did not meet the criteria above.

- Eighty-four (84) letters generated and approved by the IRB- 1504015-XP were mailed out to the remaining patients and two letters were returned undeliverable.

- No further actions on those letters were taken.

- Out of 82 eligible study participants, 52 approval letters were returned with permission to use their patient data for research.

\section{Medical facility demographics}

Family Medical Center, PLC is a single-physician owned, family medical practice located in a medically underserved community. It is located in Lawrenceburg, TN; approximately 90 miles south of Nashville, Tennessee and 90 miles Northwest of Huntsville, Alabama. The rationale for selecting this medical facility was that Lawrence County has a population of approximately 11,000 individuals with local medical access to a 99-bed hospital with no locally housed endocrinologist office within a 40 mile radius. Where many specialty providers do visit the area, endocrinologists cannot be reached without considerable transportation problems for patients. When reviewing the progress of the CMS, it is important to include patient research performed in underserved areas as well as those living in larger communities. The rational to studying patients with one provider is to establish consistency with the treatment of the patients in the study group. Using one provider will eliminate the variable of physicians with differing methods and treatment schedules.

Family Medical Center, PLC has been serving patients of any age since 2003. This organization accepts all insurance types, including patients considered to be "self-paying."

All patients diagnosed with type II DM (ICD-9 250.00) were selected before October 1, 2015 from a report generator using the organization's own certified EHR. While reviewing the total patient population at Family Medical Center, PLC, $2.5 \%$ have been diagnosed with type II DM (ICD-9 250.00). The rationale for using the type II DM (ICD-9 250.00) patient demographic is because the disease occurs in individuals of all ages; however, the disease most likely occurs in the older population of patients. 


\section{Medical record}

Two medical record systems were used during this study. The first, (EMR A) was an older generation electronic medical record which was incapable of meeting CMS quality measures. There were no patient reminders, automatic reminders of scheduled events such as office visits or pending lab work. This documentation system was strictly an EMR as it was unable to share or communicate information with any other facility; its primary purpose was to document patient visits only. This EMR was used to gather data for the first year of the study (Year 1).

The second, (EHR B) is a certified electronic health record capable of performing and reporting all CMS criteria for meeting MU and PQRS quality measures. This EHR includes automatic patient reminders for upcoming appointments, appointment tickler reminders for upcoming procedures such as lab work and pharmaceutical needs. EHR B is also capable of a consistent method of communicating with the pharmacy to assure patient compliance with filling prescribed medications. Quality control measures also remind the healthcare provider of lab work, vaccinations, and/or other procedures not yet ordered or performed. The rationale for selecting this medical record type was that it offered the opportunity to study two different electronic medical/ health recording systems in the same practice presented itself and the advantage was taken. By limiting the health care provider as a variable, focus on two entirely different systems were allowed to be studied. This EHR was used during the second year of the study (Year 2).

All data was collected from both a non-certified EMR and a certified EHR from a single-provider, family practice in rural Tennessee. The collection methods were consistently gathered for every patient to reduce variability in the samples. The timeline was set to one year previous to the implementation of a certified EHR through one year after implementation. The timeline was designed to share an equal amount of time between the two health care record systems to compare patient data results.

\section{First year data}

Patient data was retrieved from EMR A (not certified and incapable of meeting CMS Quality Control measures).

- Create a patient Record ID to link the following data with the data previously collected.

- Patient Age at time of study.

- Patient Sex.

- Date of last visit with the health care provider (between $9 / 15 / 13$ through 9/14/14)

- Document number of visits with the health care provider for the purpose of following up on type II diabetes mellitus (ICD-9 code 250.00) between $9 / 15 / 13$ and 9/14/14. Label 1, 2, 3 or 4 visits.

- Locate lab work performed between $9 / 15 / 3$ and 9/14/14. If no lab work is present, then label patient as "non-compliant." If lab work is documented, label patient as "compliant."

- Locate last LDL, BMI and HbAlc results if patient is labeled "compliant" for lab work performed between 9/15/13 and 9/14/14. Document values.

\section{Second year data}

Patient data was retrieved from EHR B (certified and capable of meeting CMS Quality Control measures).
- Document the date of last visit with the health care provider (between 9/15/14 through 9/14/15).

- Document number of visits with the health care provider for the purpose of following up on type II diabetes mellitus (ICD-9 code 250.00) between $9 / 15 / 14$ and 9/14/15. Label 1, 2, 3 or 4 visits.

- Locate lab work performed between 9/15/14 and 9/14/15. If no lab work is present, then label patient as "non-compliant." If lab work is documented, label patient as "compliant."

- Locate last LDL, BMI and HbAlc results if patient is labeled "compliant" for lab work performed between 9/15/ 14and 9/14/15 Document values.

\section{Data Analysis}

After data was collected and submitted to RedCap, it was exported into Microsoft Excel 2007 for evaluation. Individual tables were created comparing the percent change from year 1 to year 2, pertaining to patient visit compliance, lab work follow through compliance, and the lab values. While creating the bar graphs, it became obvious that the correlation between year 1 non-compliant, converting to a more compliant patient in both follow up visits as well as lab work. By separating the data from previously identified non-compliant to compliant patients, a scatter graph was created to isolate those patients and how their lab value results changed. A standard deviation and standard deviation of error will determine whether there was a significant change in lab work values, thus reinforcing the direction of change in quality of care.

The standard deviation was calculated for all the lab values as a whole, as well as data separated by initially non-compliant patients turned compliant in reference to patient follow-up visits from year 1 to year 2 [11-13].

\section{Results}

A total of 52 responses were received from the patients selected from Family Medical Center, PLC out of 84 total eligible patients diagnosed with type II, diabetes mellitus (ICD-9 250.00). Of the 84 letters of invitation to participate, 2 were returned as undeliverable, leaving 82 eligible participants in this study. The response rate of patients responding to the IRB informed consent documents to use patient data for the purpose of this study was $63.4 \%$. Of the 52 patients, there were 25 female and 27 male participants, with an average age of 66 years.

The 52 eligible patients volunteered to allow their patient data be used in this study. They were gave informed consent that no personal health information would be contained in the final report and made the informed decision to participate. Data was collected on the number follow-up visits each patient made to Family Medical Center, PLC using the last year of an older EMR system, and the first year using a new, certified EHR. Patient compliance on following through with laboratory orders was also measured for both systems. Numerical data was collected for three identifying lab work values to determine whether patient DM was to be considered under control by the patient. It was determined that 52 patients was a solid representation of the total patients studied in this practice.

\section{Data Analysis}

\section{Change in patient visits from year 1 to year 2}

$63.4 \%$ of the current type II diabetes mellitus (DM) population selected at Family Medical Center, PLC volunteered to participate in 
this study. According to the EMR records from year 1, only $38.5 \%$ were compliant with their regular, quarterly visits required by the health care provider. These patients were accepting the advice of the provider and followed-up to regular doctor's appointments.

$17.3 \%$ of the DM population studied, met provider/patient requirements by visiting the health care provider three times in the first year of study. Where four visits is ideal for compliance standards in the DM patient, those only meeting three of those visits are still considered compliant as long as their condition was under control. Combining patients visiting their primary care physician 3-4 times per year at Family Medical Center, PLC, and rated patients diagnosed with DM during year 1 at a $55.8 \%$ compliancy rate with routine office visits (Figure 1).

The correlation between patients who comply with their physician orders to visit 3-4 times in a 12 month period represents a population of patients diagnosed with type II DM, either already under control, or have been educated on the necessary measures needed to control their own disease process. These patients have chosen to take their health seriously and were expected to continue to benefit with the use of a certified EHR. As demonstrated in Table 1, by combining those patients with 3-4 visit over the first year of study, the overall difference between patient data representing those who were non-compliant with their follow-up patient visits in year 1 are corrected in the $2^{\text {nd }}$ year's data. Figure 2 is a bar graph representing patients who were compared from year 1 to year 2 . All patients in year 1 experienced a significant increase in follow up visits during year 2.

Percent Change in Patient Visits From Year 1 to Year 2

$$
\square \text { Year } 1 \quad \square \text { Year } 2
$$

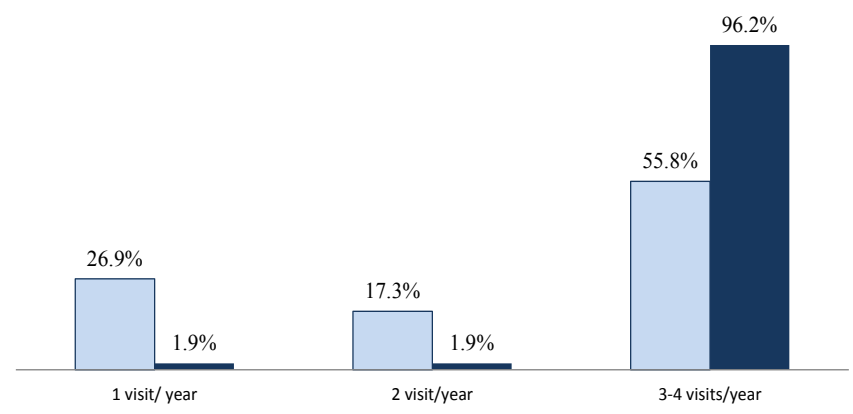

Figure 1: Percent change in patient visits from year 1 to year 2 .

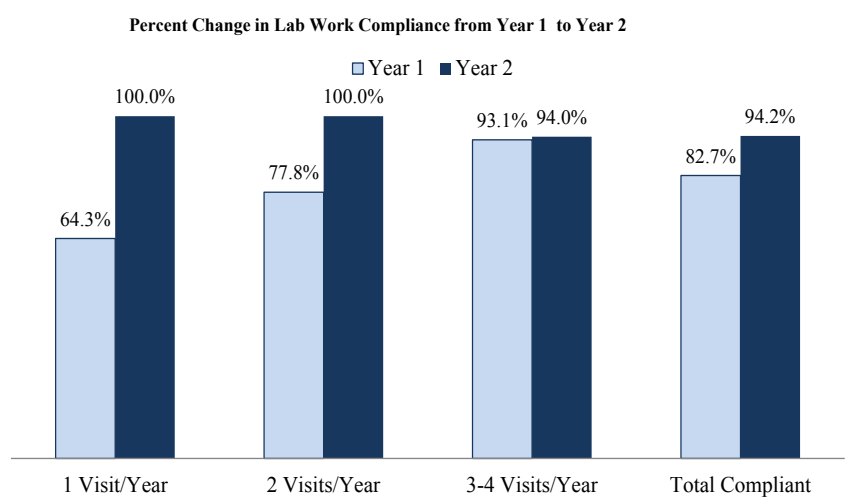

Figure 2: Percent change in lab work compliance from year 1 to year 2.

\begin{tabular}{|c|c|c|c|c|}
\hline Number of Patient Visits & Year 1 & \% Visits Year 1 & Year 2 & $\begin{array}{c}\text { \% Visits } \\
\text { Year 2 }\end{array}$ \\
\hline Patients with 1 visit/year & 14 & $26.9 \%$ & 1 & $1.9 \%$ \\
\hline Patients with 2 visits/year & 9 & $17.3 \%$ & 1 & $1.9 \%$ \\
\hline $\begin{array}{c}\text { Patients with 3-4 visits/ } \\
\text { year }\end{array}$ & 29 & $55.8 \%$ & 50 & $96.2 \%$ \\
\hline Total & 52 & $100 \%$ & 52 & $100 \%$ \\
\hline
\end{tabular}

*Note: Patients visiting their provider 3-4 times per year are considered compliant.

Table 1: Change in patient visits from year 1 to year 2.

\section{Compliance in completion of lab work from years 1 to year 2}

Overall, patients showed a $12.5 \%$ increase in lab work compliance from year 1 to year 2. Those patients exhibiting compliance with 3-4 follow-up visits per year remained consistent from year 1 to year 2 . Table 2 illustrates that patients who were non-compliant with 1-2 visits/the first year, became compliant with completing their lab work during the second year of this study. Note that this table demonstrates totals of 43 patients during year 1 and 49 patients measured for lab work compliance during year 2 . The reason for the discrepancy between 52 total patients in the study and 43 patients measured is that 9 patients were non-compliant in completing their lab work during year 1. The same goes for year two; 49 of the 52 patients were compliant in completing lab work, leaving 3 patients remaining non-compliant. What this concludes is that 7 patients who were did not participate in lab work during year 1 with the older EMR, became compliant with the new EHR during year 2. Total percentages were calculated using 52 total patients so as to disregard the non-compliant individuals. Figure 3 offers a visual representation of the comparison between patient visit compliance and patient lab work compliance. Note how those patients who began their journey as non-compliant patients, increased their visits to 3-4 times per year as well as improved when it came to lab work compliance. This demonstrates the correlation between patient, faceto-face contact with their provider, the education that is being offered, and the compliance level of that patient in regard to keeping follow-up appointments and completing their lab work orders as instructed.

\section{Change in patient low-density lipoprotein levels from year 1} to year 2

Table 3 is a combination of the three variables compared in this study. On the far left, patient overall LDL values have reduced from $92 \mathrm{mg} /$ from year $1-79 \mathrm{mg} / \mathrm{dL}$ in year 2. Looking at the data in Table 4, 43 patients were evaluated; some patients experienced dramatic reductions in their levels, where others either remained constant or even increased in their numbers. As a reminder, 9 patients were non-compliant during the year 1 EMR compilation of data, so the correlation of the $2^{\text {nd }}$ year for those same patients was disregarded for this part of the study as a percent change from year 1 to year 2 could not be calculated. The overall reduction between the two years is $14.0 \%$, where only 12 of the 43 patients exhibited an increase in LDL values from year 1 to year 2 . The standard deviation for both year 1 and year 2 are reasonably low at 0.240 and 0.199 respectively. The standard error of the mean creates confidence that these are reliable statistics. Table 4 includes the patient data collected with the standard deviation and significance levels calculated. A scatter diagram in Figure 4, located in the appendices section of this report, visually demonstrates how there is an improvement in the percent change of LDL values among patients from Year 1 to Year 2 when compared to patient visit compliance. 


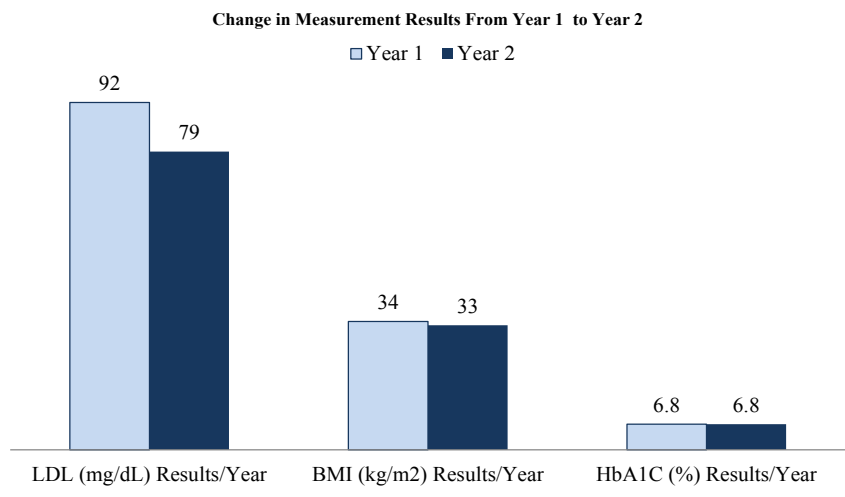

Figure 3: Change in measurement results from year 1 to year 2.

Percent Change in LDL mo/dL from Year 1 to Year 2

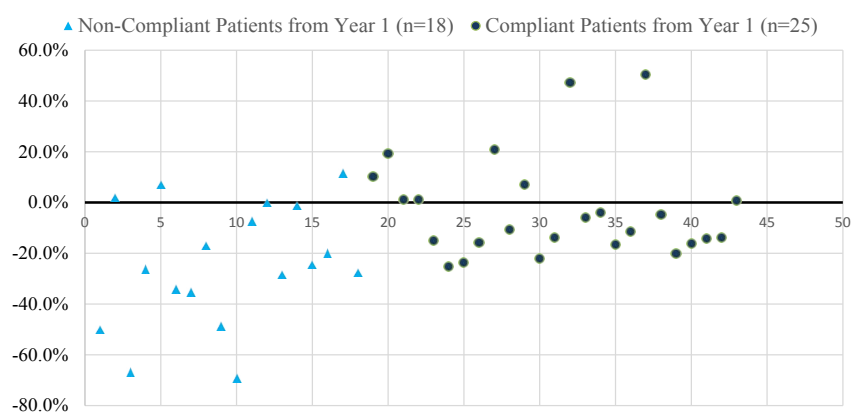

Figure 4: Percent change in LDL mg/dL from year 1 to year 2.

\begin{tabular}{|l|c|c|c|c|}
\hline Lab Work Compliance & Year 1 & $\begin{array}{c}\text { \% Compliance } \\
\text { Year 1 }\end{array}$ & Year 2 & $\begin{array}{c}\text { \% Compliance } \\
\text { Year 2 }\end{array}$ \\
\hline $\begin{array}{l}\text { Patients with 1 visit/ } \\
\text { year }\end{array}$ & 9 & $64.3 \%$ & 1 & $100.0 \%$ \\
\hline $\begin{array}{l}\text { Patients with 2 visits/ } \\
\text { year }\end{array}$ & 7 & $77.8 \%$ & 1 & $100.0 \%$ \\
\hline $\begin{array}{l}\text { Patients with 3-4 visits/ } \\
\text { year }\end{array}$ & 27 & $100.0 \%$ & 47 & $94.0 \%$ \\
\hline \multicolumn{1}{|c|}{ Total } & $43^{*}$ & $82.7 \%$ & $49^{*}$ & $94.2 \%$ \\
\hline
\end{tabular}

* Note: Year 1, 9 of the study patients were non-compliant for blood work orders filled. Year 2, 3 of the study patients were non-compliant for blood work orders filled. Compliance percentages represent these missing patients.

Table 2: Compliance in completion of lab work from year 1 to year 2.

\begin{tabular}{|c|c|c|c|}
\hline & $\begin{array}{c}\text { Year 1 } \\
\text { Average }\end{array}$ & $\begin{array}{c}\text { Year 2 } \\
\text { Average }\end{array}$ & $\begin{array}{c}\text { Average \% Decrease Lab Levels } \\
\text { Year 2 }\end{array}$ \\
\hline $\begin{array}{c}\mathrm{LDL} \\
\mathrm{n}=43\end{array}$ & $92 \mathrm{mg} / \mathrm{dL}$ & $79 \mathrm{mg} / \mathrm{dL}$ & $14.0 \%$ \\
\hline $\begin{array}{c}\mathrm{BMI} \\
\mathrm{n}=52\end{array}$ & $34 \mathrm{~kg} / \mathrm{m}^{2}$ & $33 \mathrm{~kg} / \mathrm{m}^{2}$ & $2.6 \%$ \\
\hline $\begin{array}{c}\mathrm{HbA} 1 \mathrm{c} \\
\mathrm{n}=47\end{array}$ & $6.8 \%$ & $6.8 \%$ & $0.6 \%$ \\
\hline
\end{tabular}

Table 3: Low-density Lipoprotein (LDL); Body Mass Index (BMI) and Glycosylated Hemoglobin (HbA1c) comparison from year 1 to year 2 .

\section{Change in patient body mass index values from year 1 to year 2}

Total BMI values showed very little reduction between patients in year 1 and year 2. Fifty-two patients were evaluated; some patients experienced great losses (up to 26.6\%), however the largest gain was only $6.0 \%$. Table 5 contains all the data collected during the patient visit, which is why all 52 patients are represented. The scatter diagram in Figure 5 demonstrates a population with little variation in their BMI values. The overall average is a loss for both previous non-compliant and compliant patients. The significance of this test is to demonstrate that patients diagnosed with type II diabetes mellitus should, and probably are educated on reducing carbohydrates in their diets, thus turning out a population who is able to either maintain their weight or decrease weight appropriately. Patient BMI levels are as expected in a patient population with the established diagnosis of DM. Both populations from the non-compliant patients from year 1 to year 2 have low standard deviation figures at 0.067 for year 1 and 0.590 for year 2. Together with the standard error of the mean ( 0.0140 and 0.0087 respectively), indicating a low variation in the data collected. Figure 5 in the appendices confirms the consistency of the data collected and the patient expectations as they grow from non-compliant patients to a compliant status.

\section{Change in HbAlc values from year 1 to year 2}

Table 6 includes the data collected from the patient base, minus a few patients who were unable to produce initial $\mathrm{HbAlc}$ values. There is almost no difference between the total patients from year 1 to year 2; however, dividing the patients from non-compliant follow-up visit patients from year 1, data showed a negative 2.6 decrease in $\mathrm{HbA1c}$ values to those patients who were compliant, demonstrated an increase of 2.8 percent from year 1 to year 2 . Both standard deviation of the data collected for non-compliant follow-up visit patients in year $1(0.099)$ and compliant follow-up visit patients from year $2(0.080)$ are backed

\begin{tabular}{|c|c|c|c|}
\hline \multirow{2}{*}{\multicolumn{2}{|c|}{$\begin{array}{c}\text { Non-compliant Patients from Year } 1 \\
\text { Percent Change in LDL (mg/dL) }\end{array}$}} & \multicolumn{2}{|c|}{ Compliant Patients from Year 1} \\
\hline & & \multicolumn{2}{|c|}{ Percent Change in LDL (mg/dL) } \\
\hline 1 & $-50.0 \%$ & 19 & $10.3 \%$ \\
\hline 2 & $2.0 \%$ & 20 & $19.4 \%$ \\
\hline 3 & $-66.7 \%$ & 21 & $1.1 \%$ \\
\hline 4 & $-26.3 \%$ & 22 & $1.1 \%$ \\
\hline 5 & $7.1 \%$ & 23 & $-15.2 \%$ \\
\hline 6 & $-34.1 \%$ & 24 & $-25.4 \%$ \\
\hline 7 & $-35.2 \%$ & 25 & $-23.7 \%$ \\
\hline 8 & $-17.0 \%$ & 26 & $-15.7 \%$ \\
\hline 9 & $-48.8 \%$ & 27 & $20.8 \%$ \\
\hline 10 & $-69.0 \%$ & 28 & $-10.8 \%$ \\
\hline 11 & $-7.2 \%$ & 29 & $7.2 \%$ \\
\hline 12 & $0.0 \%$ & 30 & $-22.1 \%$ \\
\hline 13 & $-28.3 \%$ & 31 & $-13.8 \%$ \\
\hline 14 & $-1.1 \%$ & 32 & $47.1 \%$ \\
\hline 15 & $-24.4 \%$ & 33 & $-5.9 \%$ \\
\hline 16 & $-19.8 \%$ & 34 & $-3.8 \%$ \\
\hline 17 & $11.7 \%$ & 35 & $-16.4 \%$ \\
\hline \multirow[t]{2}{*}{18} & $-27.6 \%$ & 36 & $-11.6 \%$ \\
\hline & & 37 & $50.5 \%$ \\
\hline $\mathrm{n}=18$ & & 38 & $-4.7 \%$ \\
\hline NC Mean & $-24.1 \%$ & 39 & $-20.0 \%$ \\
\hline Median & $-25.4 \%$ & 40 & $-16.3 \%$ \\
\hline Std. Deviation & 0.240 & 41 & $-14.3 \%$ \\
\hline \multirow[t]{7}{*}{ SD Error } & 0.0565 & 42 & $-13.6 \%$ \\
\hline & & 43 & $0.8 \%$ \\
\hline & & $n=25$ & \\
\hline & & Comp. Mean & $-3.0 \%$ \\
\hline & & Median & $-10.8 \%$ \\
\hline & & Std. Deviation & 0.199 \\
\hline & & SD Error & 0.0399 \\
\hline
\end{tabular}

Table 4: Percent change in LDL (mg/dL) from Year 1 to Year 2: Separating patients based on year 1 patient visit compliance. 
Percent Change in BMI kg/ $/ \mathrm{m}^{2}$ from Year 1 to Year 2

Non-compliant Patients from Year $1(\mathrm{n}=23) \bullet$ Compliant Patients from Year $1(\mathrm{n}=29)$ $10.0 \%$

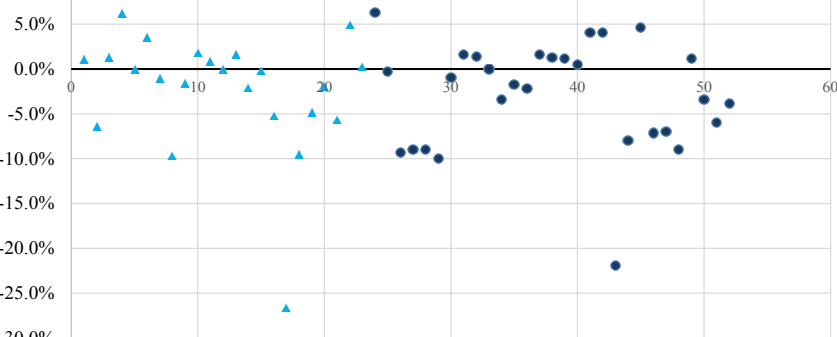

Figure 5: Percent change in $\mathrm{BMI} \mathrm{kg} / \mathrm{m}^{2}$ from year 1 to year 2.

\begin{tabular}{|c|c|c|c|}
\hline \multicolumn{2}{|c|}{ Non-compliant Patients Year 1} & \multicolumn{2}{|c|}{ Compliant Patients Year 1} \\
\hline & \multicolumn{2}{|c|}{$\%$ Change in BMI $\left(\mathrm{kg} / \mathrm{m}^{2}\right)$} \\
\hline 1 & $1.1 \%$ & 24 & $6.3 \%$ \\
\hline 2 & $-6.4 \%$ & 25 & $-0.3 \%$ \\
\hline 3 & $1.4 \%$ & 26 & $-9.3 \%$ \\
\hline 4 & $6.3 \%$ & 27 & $-9.0 \%$ \\
\hline 5 & $0.0 \%$ & 28 & $-9.0 \%$ \\
\hline 6 & $3.6 \%$ & 29 & $-10.0 \%$ \\
\hline 7 & $-1.0 \%$ & 30 & $-0.9 \%$ \\
\hline 8 & $-9.7 \%$ & 31 & $1.6 \%$ \\
\hline 9 & $-1.5 \%$ & 32 & $1.4 \%$ \\
\hline 10 & $1.8 \%$ & 33 & $0.0 \%$ \\
\hline 11 & $0.9 \%$ & 34 & $-3.4 \%$ \\
\hline 12 & $0.0 \%$ & 35 & $-1.8 \%$ \\
\hline 13 & $1.7 \%$ & 36 & $-2.2 \%$ \\
\hline 14 & $-2.1 \%$ & 37 & $1.6 \%$ \\
\hline 15 & $-0.2 \%$ & 38 & $1.3 \%$ \\
\hline 16 & $-5.2 \%$ & 39 & $1.2 \%$ \\
\hline 17 & $-26.6 \%$ & 40 & $0.5 \%$ \\
\hline 18 & $-9.5 \%$ & 41 & $4.1 \%$ \\
\hline 19 & $-4.8 \%$ & 42 & $4.1 \%$ \\
\hline 20 & $-1.9 \%$ & 43 & $-21.9 \%$ \\
\hline 21 & $-5.6 \%$ & 44 & $-8.0 \%$ \\
\hline 22 & $5.0 \%$ & 45 & $4.6 \%$ \\
\hline \multirow[t]{2}{*}{23} & $0.3 \%$ & 46 & $-7.1 \%$ \\
\hline & & 47 & $-6.9 \%$ \\
\hline $\mathrm{n}=23$ & & 48 & $-9.0 \%$ \\
\hline NC Mean & -2.3 & 49 & $1.2 \%$ \\
\hline Median & $-0.2 \%$ & 50 & $-3.4 \%$ \\
\hline Std. Deviation & 0.067 & 51 & $-6.0 \%$ \\
\hline \multirow[t]{6}{*}{ SD Error } & 0.0140 & 52 & $-3.9 \%$ \\
\hline & & $\mathrm{n}=\mathbf{2 9}$ & \\
\hline & & Comp. Mean & $-2.9 \%$ \\
\hline & & Median & $-1.8 \%$ \\
\hline & & Std Deviation & 0.059 \\
\hline & & SD Error & 0.0087 \\
\hline
\end{tabular}

Table 5: Percent change in BMI $\left(\mathrm{kg} / \mathrm{m}^{2}\right)$ from year 1 to year 2: Separating patients based on year 1 patient visit compliance.

by the standard error of the mean for both of these data sets. Figure 6 depicts a scatter diagram representing the values collected from those patients. The diagram gives a clear picture of patient fluctuation no matter how long they have been diagnosed with DM. Those patients who are either newly diagnosed, or learning to take their diabetes more seriously, represented a decrease in $\mathrm{HbAlc}$ percent which could be related to the increase in patient visits, and becoming more aware of their lab values as they trended to a more compliant status.

\section{Analysis and Discussion}

Patients diagnosed with type II diabetes mellitus (DM) require education and reminders about their disease to stay on track of patient follow-up visits and provider lab work orders. Because their condition requires consistent monitoring of particular lab values as well as medication and diet control, research has shown that there is a correlation between compliance of patient follow-up visits to the progress with improvement of lab compliance and the values collected at that time. With the implementation of a certified electronic health record (EHR), the health care professionals at Family Medical Center, PLC were able to provide patients with automatic patient reminders of appointments and lab work orders. From year 1 (using the older EMR system) to year 2 (using the certified EHR), patients were able to improve from a $44.2 \%$ non-compliancy rate for patient follow-up visits to a $3.8 \%$ non-compliancy rate the following year.

Of the 43 patients initially studied for lab work compliance, 6 patients converted from a non-compliant status to compliant after the implementation of the certified EHR. The total lab order compliant patient population grew from an $82.7 \%$ to $94.2 \%$. The data was further dissected to represent those patients who were non-compliant with follow-up visits and the correlation between patient visits and lab work compliance. The data showed a relationship between patients who visit their health care provider on a consistent basis to those who are compliant with lab work orders. There were 16 patients during the first year who were non-compliant with their follow-up visits, but were compliant with lab work orders. As follow-up order compliancy increased, the lab work order compliancy for this population hit $100 \%$ in year 2. There were 43 original compliant patients out of the original 52 for lab work orders. The second year with the certified EHR picked up 7 additional patients for lab work compliancy, thus improving those patients' lives in just one year time.

The data compiled from patient test values such as low-density lipoprotein (LDL), body mass index (BMI), and glycosylated hemoglobin (HbA1c). Total patient LDL values dropped from year 1 to year 2 by $14 \%$, thus showing significant improvement. The greatest change in overall LDL values was discovered after isolating those patients who were non-compliant with follow-up visits to the office. Those patients showed a $24.1 \%$ improvement in LDL levels than those who were compliant with their patient follow-up visits year 2 . It is possible to assess that there is a correlation between patients who are compliant with their follow-up visits with their health care provider

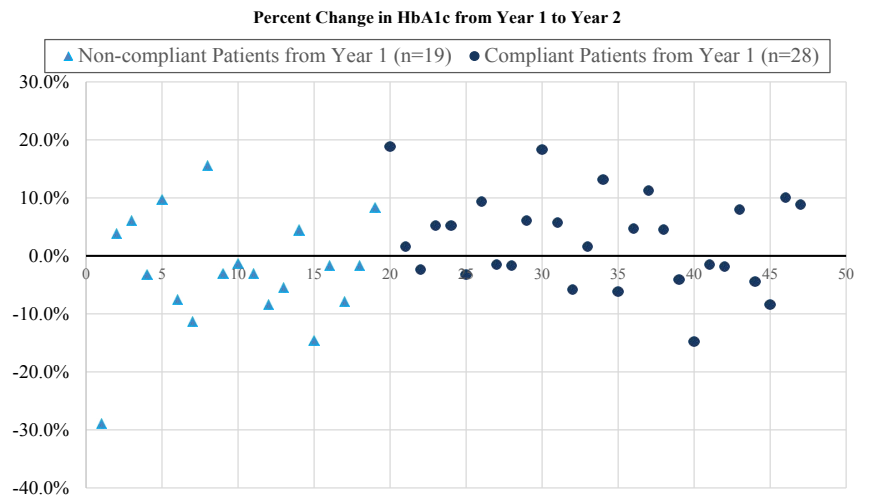

Figure 6: Percent change in $\mathrm{HbA1c}$ from year 1 to year 2. 


\begin{tabular}{|c|c|c|c|}
\hline \multirow{2}{*}{\multicolumn{2}{|c|}{$\begin{array}{c}\text { Non-compliant Patients Year } 1 \\
\% \text { Change in HbA1c (\%) }\end{array}$}} & \multicolumn{2}{|c|}{ Compliant Patients Year 1} \\
\hline & & \multicolumn{2}{|c|}{ \% Change in HbA1c (\%) } \\
\hline 1 & $-28.9 \%$ & 20 & $18.9 \%$ \\
\hline 2 & $3.9 \%$ & 21 & $1.7 \%$ \\
\hline 3 & $6.2 \%$ & 22 & $-2.4 \%$ \\
\hline 4 & $-3.2 \%$ & 23 & $5.3 \%$ \\
\hline 5 & $9.7 \%$ & 24 & $5.3 \%$ \\
\hline 6 & $-7.5 \%$ & 25 & $-3.2 \%$ \\
\hline 7 & $-11.3 \%$ & 26 & $9.4 \%$ \\
\hline 8 & $15.5 \%$ & 27 & $-1.6 \%$ \\
\hline 9 & $-3.1 \%$ & 28 & $-1.6 \%$ \\
\hline 10 & $-1.3 \%$ & 29 & $6.0 \%$ \\
\hline 11 & $-3.0 \%$ & 30 & $18.3 \%$ \\
\hline 12 & $-8.4 \%$ & 31 & $5.7 \%$ \\
\hline 13 & $-5.5 \%$ & 32 & $-5.9 \%$ \\
\hline 14 & $4.5 \%$ & 33 & $1.6 \%$ \\
\hline 15 & $-14.6 \%$ & 34 & $13.2 \%$ \\
\hline 16 & $-1.7 \%$ & 35 & $-6.2 \%$ \\
\hline 17 & $-7.8 \%$ & 36 & $4.8 \%$ \\
\hline 18 & $-1.7 \%$ & 37 & $11.3 \%$ \\
\hline \multirow[t]{2}{*}{19} & $8.3 \%$ & 38 & $4.5 \%$ \\
\hline & & 39 & $-4.1 \%$ \\
\hline $\mathrm{n}=19$ & & 40 & $-14.7 \%$ \\
\hline NC Mean & $-2.6 \%$ & 41 & $-1.4 \%$ \\
\hline Median & $-3.0 \%$ & 42 & $-1.8 \%$ \\
\hline Std Deviation & 0.099 & 43 & $7.9 \%$ \\
\hline \multirow[t]{10}{*}{ SD Error } & 0.0228 & 44 & $-4.3 \%$ \\
\hline & & 45 & $-8.4 \%$ \\
\hline & & 46 & $10.0 \%$ \\
\hline & & 47 & $8.8 \%$ \\
\hline & & & \\
\hline & & $\mathrm{n}=\mathbf{2 8}$ & \\
\hline & & NC Mean & $2.8 \%$ \\
\hline & & Median & $3.1 \%$ \\
\hline & & Std Deviation & 0.080 \\
\hline & & SD Error & 0.0159 \\
\hline
\end{tabular}

Table 6: Percent change in $\mathrm{HbA1c}(\%)$ from year 1 to year 2: Separating patients based on year 1 patient visit compliance.

and lab values directly related to their condition.

Patient BMI values showed a decrease in $2.5 \%$ in the 52 patient populations studied. When those values were separated by year 1 , noncompliant/compliant patient follow-up visits the consistency between the years remained the same. This division illustrates how patients who were non-compliant with their follow-up visits with the health care provider, showed $0.6 \%$ less improvement than those patients who were compliant with both the EMR and certified EHR.

It wasn't until the HbAlc values were separated before again, a correlation between patients who established follow-up visit compliancy between year 1 and year 2 and those who were compliant for both years. The 19 patients who improved their compliancy status also improved in their overall $\mathrm{HbAlc}$ values by $2.6 \%$. Those patients who were compliant with their follow-up visits with the EMR and certified EHR increased their percent average HbAlc by 3.0\%. Otherwise, total change in $\mathrm{HbAlc}$ percent for all patients included in the study rests at a $0.6 \%$ increase.

Not all patients started at the same point of their diagnosis and disease process on year 1. It is expected to see some fluctuation in lab value numbers and patient visits as the changes in the EHR arose. It is important to remember that all patients are different and there will be some outliers no matter how the study is conducted. However, even some of the non-compliant patients from year 1 could have been diagnosed for years, but just now received information to encourage them to exceed their original expectations. Some of these patients could be newly diagnosed and either in denial about their condition, or embraced the change completely. Without this information, it is impossible to start every patient off at the same point. However, the purpose of this study is to demonstrate improvement over a two year period, using an older EMR which was incapable of meeting MU, and a new, certified EHR designed to improve overall patient care by meeting the MU initiatives introduced by the CMS.

This study was conducted over a two year period. The first year evaluated patient compliance with patient follow-up visits, lab orders and lab values using an older EMR system which was not capable of meeting MU. This is significant because without benefit of patient reminders and follow-up controls for compliance, patients with DM were not tracked as well as they were with the certified EHR. The changes were evaluated after one year; this time period may not have been long enough produce significant results.

\section{Conclusions}

The results in this study strongly suggest that those eligible participants who are invested in a certified EHR can offer the convenience of automatic reminders about patient follow-up visits and lab work compliance. The added communication between patients and their health care provider improves patient compliance. Even though there was only a year to study the lab work values and BMI changes in patients diagnosed with type II diabetes mellitus, the current trend correlates that increased patient/provider face-to-face meetings can offer patients the chance to improve the quality of their health care by attaining more educational materials and direction from their health care provider. Research indicates that an educated patient is a compliant patient. Patients compliant with their health care provider orders are capable of improving their health if they choose to adhere to the plan.

\section{Acknowledgement}

Authors would like to express sincere gratitude to Prof. Rebecca R. Reynolds, EdD, RHIA, Department of Health Informatics and Information Management UTHSC, for the support and encouragement while pursuing this work. The authors have no financial interests or conflicts of interest with any of the corporations or products mentioned.

\section{References}

1. Centres for Medicare and Medicaid Services (2010) Medicare and Medicaid EHR incentive program.

2. Centres for Medicare and Medicaid Services.

3. Crosson JC, Ohman-Strickland PA, Cohen DJ, Clark EC, Crabtree BF (2012) Typical electronic health record use in primary care practices and the quality of diabetes care. Ann Fam Med 10: 221-227.

4. Ahmad FS, Tsang T (2012) Diabetes prevention, health information technology, and meaningful use: Challenges and opportunities. American Journal of Preventative medicine 44: 357-363.

5. Centres for Medicare and Medicaid Services (2014) Eligible professional meaningful use core measures: Measure p: 10.

6. Sharp SE, Miller MB, Hindler J (2015) Individualized Quality Control Plan (IQCP): Is It Value-Added for Clinical Microbiology? J Clin Microbiol 53: 37193722.

7. Centres for Medicare and Medicaid Services (2015) Physician Quality Reporting System: About PQRS.

8. American Medical Association (2015) Physician quality reporting system. 
Citation: Hines TA, Kumar S (2016) Certified Electronic Health Records and Quality of Health Care in Type II Diabetes Mellitus Patients. J Health Med Informat 7: 231. doi:10.4172/2157-7420.1000231

Page 8 of 8

9. American Diabetes Association (2009) Diagnosis and classification of diabetes mellitus. Diabetes Care 32: S62-S67.

10. Berryman SH, Sick BT, Qi W, Swan PJ, Marie Weber-Main A (2013) Use of automated reminder letters to improve diabetes management in primary care: outcomes of a quality improvement initiative. Quality In Primary Care 21: 359-368.

11. Osborn CE (2008) Essentials of Statistics in Health Information Technology. MA: Jones and Bartlett Publishers, Inc, Sudbury.

12. Anker J, Kern L, Edwards A, Nosal S, Stein D, et al. (2015) Associations between healthcare quality and use of electronic health record functions in ambulatory care. Journal of the American Medical Informatics Association 22: 864-871.

13. Benhamou PY (2011) Improving diabetes management with electronic health records and patients' health records. Diabetes Metab 37: S53-S56.
14. Patel V, Reed ME, Grant RW (2015) Electronic health records and the evolution of diabetes care: a narrative review. J Diabetes Sci Technol 9: 676-680.

15. Reed M, Huang J, Graetz I, Brand R, Hsu J, et al. (2012) Outpatient electronic health records and the clinical care and outcomes of patients with diabetes mellitus. Ann Intern Med 157: 482-489.

16. Schnipper JL, Cornell DP, Linder JA, Palchuk MBT, Einbinder JS, et al. (2008) "Smart Forms" in an electronic medical record: Documentation-based clinical decision support to improve disease management. Journal of the American Medical Informatics Association 18: 513-519.

17. Sideman J (2011) EMR vs. EHR-What is the difference?

18. Varroud-Vial M (2011) Improving diabetes management with electronic medical records. Diabetes Metab 37: S48-S52. 